\title{
Control Parametric Analysis on Improving Park Restoring Force Model and Damage Evaluation of High-Strength Structure
}

\author{
Huang-bin Lin, ${ }^{1}$ Shou-gao Tang, ${ }^{1}$ and Cheng $\operatorname{Lan}^{2}$ \\ ${ }^{1}$ School of Aerospace Engineering and Applied Mechanics, Tongji University, Shanghai 200092, China \\ ${ }^{2}$ Bolina Ingegneria SR., Mestre, 30173 Venice, Italy \\ Correspondence should be addressed to Huang-bin Lin; 1110448@tongji.edu.cn
}

Received 1 May 2016; Revised 9 July 2016; Accepted 11 July 2016

Academic Editor: Antônio G. de Lima

Copyright (C) 2016 Huang-bin Lin et al. This is an open access article distributed under the Creative Commons Attribution License, which permits unrestricted use, distribution, and reproduction in any medium, provided the original work is properly cited.

\begin{abstract}
In the dynamic time-history analysis of structural elastoplasticity, it is important to develop a universal mathematical model that can describe the force-displacement characteristics for restoring force. By defining three control parameters (stiffness degradation, slip closure $\gamma$, energy degradation $\beta$ ), the Park restoring force mathematical model can simulate various components. In this study, the Park restoring force has been improved by adding two control parameters (energy-based strength degradation $\beta_{e}$ and ductilitybased strength degradation $\beta_{d}$ ). Based on the testing data, the constitutive model is input and 55 numerical models are developed to analyze the effects of various parameters on structural behavior. Conclusion. (1) $\beta$ has determinative effect on structural behavior; the effect of $\beta_{e}$ is basically consistent with that of $\beta ; \alpha$ has significant effect on shear forces and bending moments; $\gamma$ has significant effect on displacements and accelerations; $\beta_{d}$ has significant effect on shearing forces, acceleration, and total energy consumptions. (2) Based on the classification of four types of damage level, the recommended values for $\alpha, \gamma, \beta, \beta_{e}$, and $\beta_{d}$ are presented. (3) Based on the testing data of high-strength columns, the recommended values for the five control parameters of the improved Park restoring force model are presented.
\end{abstract}

\section{Introduction}

In structural seismic analysis, the mechanical responses of materials and structural members under the action of elastoplastic dynamic load are important [1]. And in these elastoplastic analyses, the restoring force model is playing the key role. Restoring force models are mathematical models established to describe restoring force and deformation according to the simplified relation curve between restoring force and deformation, where the most essential issue is how to accurately define and program a mathematical model for the restoring force in order to describe the structural member levels in the program. Currently, the most commonly adopted restoring force mathematical models are including the Polygonal Hysteretic Model (PHM) and the Smooth Hysteretic Model (SHM) [2,3]. For restoring force models targeting structural member levels, mathematical expressions are mainly created through experimental studies on structural members, in which case sufficient preliminary testing data are needed to establish restoring force models through numerical fitting. When developing the program Inelastic Damage Analysis of Reinforced Concrete (IDARC), Park proposed the Triparameter-Park restoring force model [4], a mathematical model for restoring force that takes into account stiffness degradation, strength degradation, pinching slip, and other structural effects. The model is also subjected to the synchronous control by three parameters, that is, the stiffness degradation-based parameter $\alpha$, the energy degradation-based parameter $\beta$, and the pinching degradation-based parameter $\gamma$.

The program IDARC adopts PHM and SHM [5] too, the former of which is mainly used to describe the restoring force performance of concrete structures, while the latter [6] is applied to the simulation of the restoring force hysteretic performance of steel structures. IDARC is a program jointly developed by University at Buffalo, the State University of New York, and The Earthquake Engineering Research Center, which is applied for nonlinear dynamic response time-history analysis and damage analysis in various types of structures. The three control parameters, stiffness degradation-based 


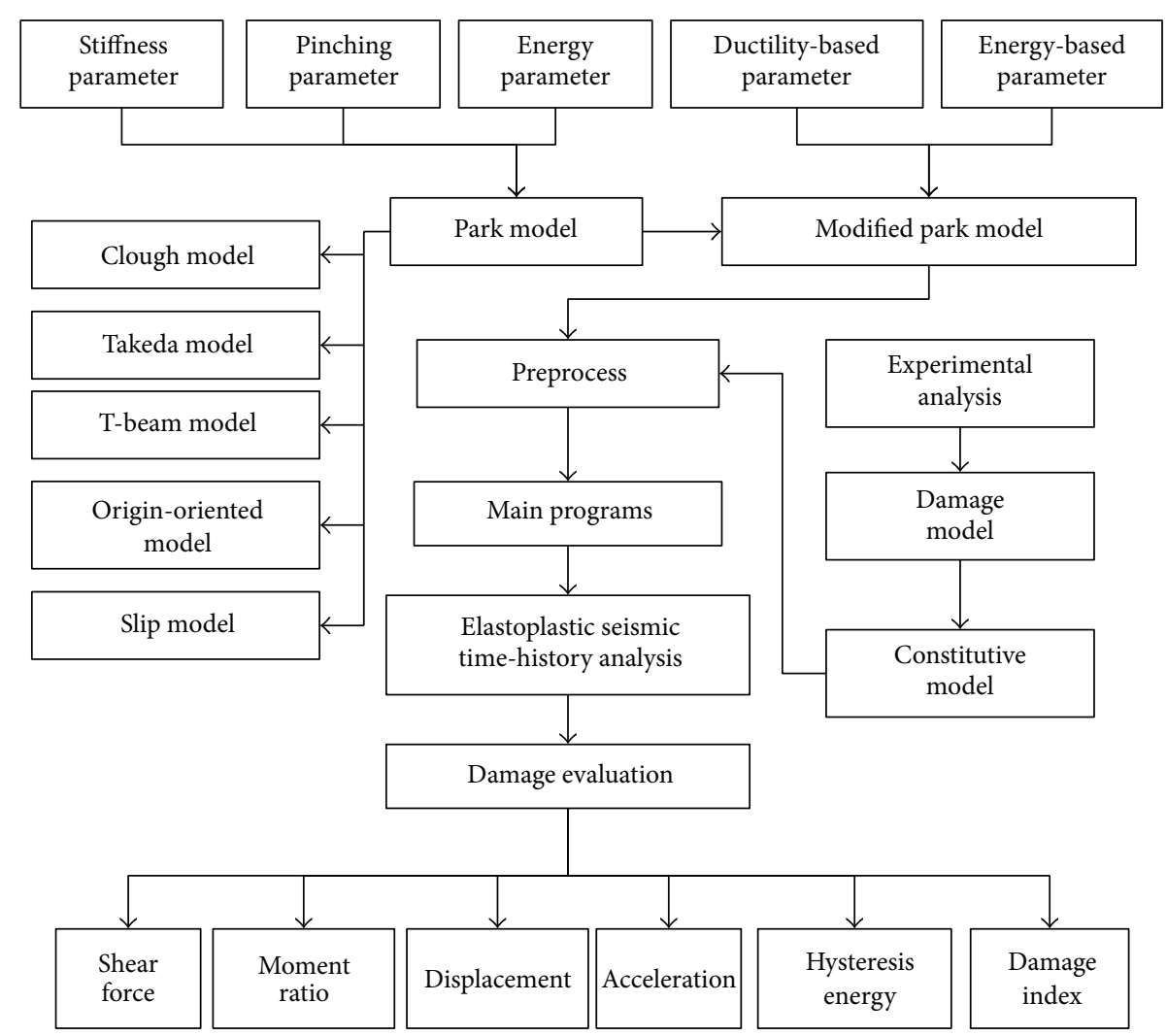

Scheme 1: Programming flowchart.

parameter $\alpha$, energy degradation-based parameter $\beta$, and pinching degradation-based parameter $\gamma$, can be employed to determine stiffness degradation, energy degradation, and pinching effects. In particular, when $\alpha \Rightarrow \infty, \beta=0$, and $\gamma \Rightarrow \infty$, the Clough model can be obtained [7], while when $\alpha=2.0, \beta=0.1$, and $\gamma \Rightarrow \infty$, the Takeda model can be obtained [8]. Through parameters adjustment, the model can be also employed to simulate the T-Beam restoring force model, the shear wall restoring force model, and the masonry structure restoring force model: with $\alpha=2.0, \beta=0.1$, and $\gamma=0.5$, the T-Beam model can be stimulated [5]; with $\alpha \Rightarrow 0$, $\beta \Rightarrow 0$, and $\gamma \Rightarrow \infty$, the origin-oriented model can be simulated [9]; and with $\alpha \Rightarrow \infty, \beta \Rightarrow 0$, and $\gamma \Rightarrow 0$, the slip restoring force model can be simulated [5]. Therefore, this is a universal model that can be applied to the simulation of various types of structural members.

The modified Park model is to be presented as follows. Based on Clough's and Takeda's models, it is a new universal PHM model established by borrowing the strength of the Triparameter-Park restoring force model, featured by vertexoriented and yield-oriented behaviors. The modified Park restoring force model also takes into account the strength degradation due to energy dissipation and ductility, and it leads to a five-parameter control of the restoring force mathematical model by introducing two additional parameters, that is, the energy-based strength degradation parameter $\beta_{e}$ and the ductility-based strength degradation parameter $\beta_{d}$. A schematic diagram of the methodology of this paper is shown in Scheme 1.

\section{Modified Park Restoring Force Model and Five Control Parameters}

The Triparameter-Park restoring force model is a mathematical model controlled by three parameters, that is, the stiffness degradation parameter $\alpha$, the strength degradation parameter $\beta$, and the pinching degradation parameter $\gamma$. The modified Park restoring force model is controlled by five control parameters, that is, the stiffness degradation parameter $\alpha$, the ductility-based strength degradation parameter $\beta_{d}$, the energy-based strength degradation parameter $\beta_{e}$, the pinching degradation parameter $\gamma$, and the strength degradation parameter $\beta$.

(1) Stiffness Degradation Parameter $\alpha$. It is used to control the stiffness degradation process of the unloading segment of the restoring force model of structural members. All the unloading lines intersect in opposite directions at one point with vertical coordinate ( $y$-axis) $\alpha M_{y}$ :

$$
\begin{aligned}
R_{K}^{+} & =\frac{M_{\text {cur }}+\alpha M_{y}}{K_{0} \emptyset_{\text {cur }}+\alpha M_{y}}, \\
K_{\text {cur }} & =R_{K} K_{0}, \\
K_{\text {cur }} & =\frac{M_{\text {cur }}+\alpha M_{y}}{K_{0} \emptyset_{\text {cur }}+\alpha M_{y}} K_{0} .
\end{aligned}
$$

$M_{\text {cur }}$ is current moment; $\emptyset_{\text {cur }}$ is current curvature; $R_{K}$ is stiffness degradation factor; $K_{0}$ is initial elastic stiffness; $K_{\text {cur }}$ 
is current stiffness (wherein, when $\left(M_{\text {cur }}, \emptyset_{\text {cur }}\right)$ is on the right side of the elastic segment, $M_{y}=M_{y}^{+}$; when $\left(M_{\text {cur }}, \emptyset_{\text {cur }}\right)$ is on the left side of the elastic segment, $\left.M_{y}=M_{y}^{-}\right) ; \alpha$ is stiffness degradation parameter, with a value range of $\alpha \in(200.0,0.0)$.

(2) Energy Degradation Parameter $\beta$. It is used to set the ratio between the damage increment caused by the increment of the maximum displacement response $d \delta_{m} / \delta_{u}$ and by the normalized hysteretic energy dissipation increment $d E / \delta_{u} Q_{y}$. Park et al. [4] defined an energy degradation parameter when programming the restoring force model of IDARC, and they also adopted this parameter $\beta$ in the subsequent energy-deformation two-parameter damage model used for the calculation of structural damage [10]:

$$
\begin{aligned}
& \beta=\frac{d \delta_{m} / \delta_{u}}{d E / \delta_{u} Q_{y}}=\frac{d \delta_{m}}{d E / Q_{y}}, \\
& \beta=\left(-0.447+0.037 \frac{l}{d}+0.24 n_{0}+0.314 \rho_{t}\right) \times 0.7^{\rho_{w}} .
\end{aligned}
$$

$d \delta_{m}$ is increment of the maximum displacement; $\delta_{u}$ is ultimate displacement; $d E$ is hysteretic energy dissipation increment; $Q_{y}$ is yield strength; $l / d$ is shear-span ratio; $n_{0}$ is axial compression ratio; $\rho_{t}$ is longitudinal reinforcement ratio; $\rho_{w}$ is stirrup ratio.

The modified Park restoring force model, as introduced, adopts the mathematical forms of the ductility-based strength degradation parameter $\beta_{d}$ and the energy-based strength degradation parameter $\beta_{e}$. The parameters in the literature $[5,11]$, based on the definitions of energy degradation parameters, are used to describe the strength degradation process of structural members caused by different factors, such as energy dissipation and ductility. The parameter $\beta$ is employed to define $\beta_{d}$ and $\beta_{e}$, based on two types of restoring force hysteretic curve rules:

$$
\begin{aligned}
M_{y}^{+/-} & =M_{y 0}^{+/-}\left[1-\left(\frac{\emptyset_{\max }^{+/-}}{\emptyset_{u}^{+/-}}\right)^{1 / \beta_{d}}\right]\left[1-\frac{\beta_{e}}{1-\beta_{e}} \frac{H}{H_{\mathrm{ult}}}\right], \\
\Delta H & =\left[\frac{M+(M+\Delta M)}{2}\right]\left(\Delta \emptyset-\frac{\Delta M}{R_{K} K_{0}}\right) .
\end{aligned}
$$

$\beta_{d}$ is ductility-based strength degradation parameter; $\beta_{e}$ is energy-based strength degradation parameter (wherein, the presence of the term $\beta_{d}$ represents the strength degradation of deformation and ductility increment, and the presence of the term $\beta_{e}$ represents the strength degradation of hysteretic energy dissipation, and $\Delta H$ represents the hysteretic energy dissipation increment); $M_{y}^{+/-}$is positive or negative yield moment; $M_{y 0}^{+/-}$is initial positive or negative yield moment; $\emptyset_{\max }^{+/-}$is positive or negative maximum curvature; $\emptyset_{u}^{+/-}$is positive or negative ultimate curvature; $M$ is moment; $\Delta M$ is moment increment; $H$ is hysteretic energy dissipation; $H_{\text {ult }}$ is hysteretic energy dissipation of monotonic load under nondegraded ultimate curvature, with value ranges of $\beta_{e} \in$ $(0.0,0.6)$ and $\beta_{d} \in(0.0,0.6)$.
(3) Gap Closure Slip Degradation Parameter $\gamma$. It is introduced to describe the typical effects of fracture opening and closure, crack closure and bond slip caused by slip and pinching, and so forth. Slip is a phenomenon in which simulation is adopted, as the target point of loading for the crack closure point and the toward point of the loading force is a partial value of the yield moment, with a value range of $\gamma \in(1.0,0.0)$ :

$$
\begin{aligned}
M_{\gamma} & =\gamma M_{y}, \\
\emptyset \gamma & =\gamma \emptyset_{\gamma y}+(1-\gamma) \emptyset_{\gamma u} .
\end{aligned}
$$

$M_{y}$ is yield moment; $\emptyset_{u}$ is ultimate curvature; $M_{\gamma}$ is moment caused by slip and pinching; $\emptyset_{\gamma}$ is curvature caused by slip and pinching; $\emptyset_{\gamma y}$ is yield curvature caused by slip and pinching; $\emptyset_{\gamma u}$ is ultimate curvature caused by slip and pinching.

\section{Control Parameter Analysis of the Modified Park Restoring Force Model}

The modified Park restoring force model, based on different valuation methods for $\alpha, \beta$, and $\gamma$, is able to simulate different structural member characteristics, such as the Clough model, the Takeda model, the origin-oriented model, and the slip model. This model has relatively high universality when it comes to mathematical models describing the restoring force, so that it applies to universally describe the different restoring force models and to establish the relation between generalized force and generalized displacement in the elastoplastic dynamic time-history analyses of different structures. The modified Park model provides four control parameters to describe the constitutive relation, which is incomparable to other typical restoring force models. In the comparison carried out, the Smooth model [3] shows an advantage in terms of reducing calculation loops in the synchronous processing of motion equations, but it only applies to the description of state space.

(1) Stiffness Degradation Parameter $\alpha$. It is used to describe the degree of stiffness degradation, and its value variations describe the degree of stiffness degradation of the restoring force in the hysteretic process in four ranges; in the value range of (0 200), $\alpha$ can satisfy the simulation of the restoring force performance of conventional structural members. Some studies have adopted the stiffness degradation parameter $\alpha$ to distinguish between bent members and shear members or to reach the conclusion that it exerts no influence on the strength or stiffness of structural members. There has been no systematic study devoted to quantitatively exploring the degree of influence of stiffness degradation parameter $\alpha$.

(2) Fracture Slip Closure Parameter $\gamma$. It is used to describe the degree of fracture slip closure of the restoring force of structural members in the hysteretic process in four ranges; in the value range of $(0 \sim 1.0), \gamma$ can satisfy the simulation of the restoring force performance of conventional structural members. There has been no systematic study devoted to quantitatively exploring the degree of influence of fracture slip closure parameter $\gamma$. 
(3) Energy Degradation Parameter $\beta$. A fitted expression of $\beta$ is given in studies on the Park deformation-energy dissipation two-parameter damage model. The expressions of parameters $\delta_{u}$ and $\beta$ are obtained through the fitting analysis of the test data of 402 rectangular-section concrete columns and $132 \mathrm{H}$-section steel columns [12]. In a study conducted in 2013, Rajabi et al. [13] proposed that the value of $\beta$ should be set at 0.27 based on probability, with a standard deviation of 0.6 , and they claimed that putting forward the fitted formula in the value range of (0.1-0.6) in the program would make it more applicable to the simulation of the structural members tested. Through some tests, the study [14] has obtained the expression of $\beta$; Chinese scholars [15] have also conducted some studies on energy parameter-based valuations. In the technical report of IDARC 7.0 [5], the value range of $\beta$ is $(0 \sim 0.6)$. With the constant increase of both the experimental reinforcement ratio of concrete columns and the strength of concrete, in the latest structural test of the studying team [16], the deficiencies of energy degradation parameter $\beta$ have been constantly verified by structural tests. However, to obtain the fitted and universal expression of $\beta$, the different tests and systematic studies and analyses are necessary. When the parameter $\beta$ adopts the ductility-based strength degradation parameter $\beta_{d}$ and the energy-based strength degradation parameter $\beta_{e}$, the restoring force model and damage evaluation are better described.

Nevertheless, it is necessary to analyze the influence of the parameters on internal forces of structural members (shear and moment ratio), structural responses (displacement and acceleration values), and structural damage (structural energy dissipation and damage value) and the influence of the values of energy degradation $\beta_{d}$ and $\beta_{e}$ on internal forces of structural members, structural responses, and structural damage.

\section{Simulation Analysis of Test and Numerical Model}

4.1. Test Data of the Numerical Model. Based on the testing data obtained in the preliminary stage, a test was conducted on the seismic performance of HRB400 high-strength concrete columns, and a nonlinear analysis was carried out in quasistatic loading of structural members. The test is detailed in the reference papers of Lin and Wang [17]. Tables 1 and 2 provide the main test data of structural members and the measured data of concrete and reinforcement materials. IDARC preprocessor was adopted to set model parameters, and El Centro seismic wave was selected from the PEER Strong Motion Database. In the preliminary work done by Lin and Wang [18], IDARC program employed test data to conduct numerical simulation verification, the results of which revealed the feasibility of applying IDARC program to the damage analysis and evaluation of high-performance concrete structures.

\subsection{Test Data of the Numerical Model}

(1) Constitutive Relation of Concrete. The concrete, to adopt an unrestricted constitutive model, exploits the Kent-Park constitutive model [19] modified by Scott et al. [20], consisting of an ascending segment and a descending segment:

$$
\begin{aligned}
& \sigma^{-}=K f_{c}\left[2\left(\frac{\varepsilon^{-}}{\varepsilon_{p}^{-}}\right)-\left(\frac{\varepsilon^{-}}{\varepsilon_{p}^{-}}\right)^{2}\right], \quad \varepsilon^{-} \leq \varepsilon_{p}^{-}, \\
& \sigma^{-}=K f_{c}\left[1-Z\left(\varepsilon^{-}-\varepsilon_{p}^{-}\right)\right] \geq 0.2 K f_{c}, \quad \varepsilon_{p}^{-} \leq \varepsilon^{-} \leq \varepsilon_{u}^{-}, \\
& \varepsilon_{p}^{-}=0.002 K, \quad K=1+\frac{\rho_{s} f_{y h}}{f_{c}},
\end{aligned}
$$

Z

$$
=\frac{0.5}{\left(3+0.29 f_{c}\right) /\left(145 f_{c}-1000\right)+0.75 \rho_{s} \sqrt{h^{\prime} / s_{h}-\varepsilon_{p}^{-}}} .
$$

$\varepsilon_{p}^{-}$represents the strain corresponding to the stress peak; $K$ represents the strength enhancement coefficient of concrete under the confinement of stirrups; $Z$ represents the strain softening angle of concrete; $f_{c}$ represents the compressive strength of concrete; $f_{y h}$ represents the stirrup yield strength; $\rho_{s}$ represents the ratio between the stirrup volume and the core concrete volume; $s_{h}$ represents the stirrup spacing. The numerical model values in the program are $\varepsilon_{p}^{-}=0.203 \%, f_{c}=53 \mathrm{MPa}, f_{y h}=390 \mathrm{MPa}$, and $s_{h}=$ $150 \mathrm{~mm}$; for other values refer to the test data in Tables 1 and 2, while the Default value of $Z$ is calculated based on the program.

(2) Constitutive Relation of Reinforcement. The reinforcement adopts the ideal elastoplastic constitutive model, without taking into account the stress growth caused by strain hardening:

$$
\begin{aligned}
& \sigma_{s}=E_{s} \cdot \varepsilon_{s} ; \quad 0 \leq \varepsilon_{s} \leq \varepsilon_{s y}, \\
& \sigma_{s}=f_{y} ; \quad \varepsilon_{s y}<\varepsilon_{s} \leq \varepsilon_{s 0}, \\
& \sigma_{s}=f_{y}+E_{s}^{p} \cdot\left(\varepsilon-\varepsilon_{0}\right) ; \quad \\
& \quad E_{s}^{p}=0.025 E_{s}, \varepsilon_{s 0}<\varepsilon_{s} \leq \varepsilon_{s u},
\end{aligned}
$$

$\sigma_{s}=0 ; \quad \varepsilon_{s u}<\varepsilon_{s}$

$\varepsilon_{s}$ represents the reinforcement strain; $\sigma_{s}$ represents the reinforcement stress; $E_{s}$ represents the elastic modulus of reinforcement; $f_{y}$ represents the yield stress of reinforcement; $E_{s}^{p}$ represents the equivalent elastic modulus of strengthening stage; $\varepsilon_{s 0}$ represents the strain of strengthening stage; $\varepsilon_{s u}$ represents the ultimate strain of reinforcement. Numerical model values are $\varepsilon_{s y}=3 \%$ and hardening segment of reinforcement $E_{s}^{p}=3416 \mathrm{MPa}$; for other values refer to the test data in Tables 1 and 2.

4.3. Numerical Modeling. The constitutive relation was implemented based on test results in the preliminary stage [16], and the IDARC was adopted to conduct an elastoplastic dynamic time-history analysis on the test pieces. Programming different restoring force model control parameters, 
TABLE 1: Main information of test components in structural test.

\begin{tabular}{|c|c|c|c|c|c|c|}
\hline $\begin{array}{l}\text { Designed concrete } \\
\text { strength grade }\end{array}$ & $\begin{array}{l}\text { Axial compression ratio } \\
\qquad n=N / f_{c k b h}\end{array}$ & $\begin{array}{l}\text { Longitudinal } \\
\text { reinforcement }\end{array}$ & Stirrup & $\begin{array}{c}\text { Shear-span ratio } \\
\lambda=H / h_{0}\end{array}$ & $\begin{array}{c}\text { Longitudinal } \\
\text { reinforcement ratio } \\
\rho_{s v}\end{array}$ & $\begin{array}{c}\text { Stirrup ratio } \\
\rho_{s v}\end{array}$ \\
\hline C60 & 0.20 & 4 뾰 25 & $\Phi 10 @ 150$ & 1.9 & $3.70 \%$ & $0.269 \%$ \\
\hline
\end{tabular}

TABLE 2: Measured material performance data of test piece.

\begin{tabular}{lccccc}
\hline Elastic modulus & Yield strength & Yield strain & Ultimate tensile strength & $f_{\text {cu }}(\mathrm{MPa})$ & $f_{c}(\mathrm{MPa})$ \\
$E_{s}(\mathrm{GPa})$ & $f_{y}(\mathrm{MPa})$ & $f_{t}(\mu \varepsilon)$ & $f_{b}(\mathrm{MPa})$ & 57.1 & 53 \\
\hline 202 & 450 & 2233 & 585 & 3.47 \\
\hline
\end{tabular}

Note: $E_{s}$ : elastic modulus of reinforcement; $f_{y}$ : yield strength of reinforcement; $\varepsilon_{y}$ : yield strain of reinforcement; $f_{b}$ : ultimate tensile strength of reinforcement. $f_{\text {cu }}$ : cubic compressive strength of concrete. $f_{c}$ : axial compressive strength of concrete. $f_{t}$ : compressive strength of concrete. $\mu \varepsilon: 10^{-6}$ strain.

shear, moment ratio, displacement response, acceleration response, structural total energy dissipation, and structural cumulative damage value of high-performance columns under different parameter levels were obtained. The influence of different parameter levels on the above six structural responses was also analyzed. After establishing a total of 55 models, the data of the first three groups, that is, (1)-(3), were adopted to comparatively analyze the relations between the energy degradation parameter $\beta$ on one hand and the stiffness degradation parameter $\alpha$ and the fracture slip closure parameter $\gamma$ on the other hand, while the data of the last three groups, that is, (3)-(4), were adopted to comparatively analyze the relations between the energy degradation parameter $\beta$ on one hand and the ductility-based strength degradation parameter $\beta_{d}$ and the energy-based strength degradation parameter $\beta_{e}$ on the other hand.

(1) Stiffness Degradation Parameter $\alpha . \alpha$ was given a total of 11 independent parameter controlled variables, that is, 200, 135, 91, 62, 42, 28, 19, 13, 9, 6 and 4; the fracture slip pinching parameter $\gamma$ was set at its Default value, and the energy degradation parameter $\beta$ was also set at its Default value (numbered as $\alpha_{1} \sim \alpha_{11}$, a total of 11 models). For the convenience of comparative expression in the same range, $\alpha$ was provided with normalization processing, so that $\alpha \in$ $(1.0,0.0)$.

(2) Slip Pinching Parameter $\gamma \cdot \gamma$ was given a total of 11 independent parameter variables, that is, $1.0,0.91,0.81,0.72$, $0.62,0.53,0.43,0.34,0.24,0.15$, and 0.05 ; the stiffness degradation parameter $\alpha$ was set at its Default value, and the energy degradation parameter $\beta$ was also set at its Default value (numbered as $\gamma_{1} \sim \gamma_{11}$, a total of 11 models). A value range was given to ensure that $\gamma \in(1.0,0.0)$.

(3) Energy Degradation Parameter $\beta$. $\beta$ was given a total of 11 independent parameter variables, that is, $0.01,0.07,0.13$, $0.19,0.25,0.31,0.36,0.42,0.48,0.54$, and 0.60 ; the stiffness degradation parameter $\alpha$ was set at its Default value, and the slip pinching parameter $\gamma$ was also set at its Default value (numbered as $\beta_{1} \sim \beta_{11}$, a total of 11 models). For the convenience of comparative expression in the same range, $\beta$ was provided with normalization processing, so that $\beta \epsilon$ $(0.0,1.0)$.

(4) Ductility-Based Strength Degradation Parameter $\beta_{d} \cdot \beta_{d}$ was given a total of 11 independent parameter variables, that is, $0.01,0.07,0.13,0.19,0.25,0.31,0.36,0.42,0.48,0.54$, and $0.60 ; \beta_{e}=0.01, \alpha=200$, and $\gamma=1.0$ (numbered as $\beta_{d_{1}} \sim \beta_{d_{11}}$, a total of 11 models). $\beta_{d}$ was provided with normalization processing, so that $\beta_{d} \in(0.0,1.0)$.

(5) Energy-Based Strength Degradation Parameter $\beta_{e}$. $\beta_{e}$ was given a total of 11 independent parameter variables, that is, $0.01,0.07,0.13,0.19,0.25,0.31,0.36,0.42,0.48,0.54$, and 0.60 ; $\beta_{d}=0.01, \alpha=200$, and $\gamma=1.0$ (numbered as $\beta_{e 1} \sim \beta_{e 11}$, a total of 11 models). $\beta_{e}$ was provided with normalization processing, so that $\beta_{e} \in(0.0,1.0)$.

\section{Analysis of Influence of Control Parameters on Structural Responses and Damage}

After performing elastoplastic dynamic time-history analyses on the 55 numerical models established, the results are analyzed and summarized in the following paragraphs.

5.1. Analysis of Influence of Control Parameters $\alpha, \beta$, and $\gamma$ on Structural Responses and Damage. As depicted in Figure 1, there are the influences on various main structural responses of the numerical model due to varying values of the energy degradation-based parameter $\beta$, of the stiffness degradationbased parameter $\alpha$, and of the fracture slip closure parameter $\gamma$. The influences are also listed out for different value ranges of parameters $\alpha, \beta$, and $\gamma$, in Tables 3,4 , and 5 , respectively.

$\uparrow \uparrow \uparrow$ means significantly increased; $\uparrow \uparrow$ means obviously increased; $\uparrow$ means slightly increased; $\rightarrow$ means slightly unchanged.

$\downarrow$ means slightly decreased; $\downarrow \downarrow$ means obviously decreased; $\downarrow \downarrow \downarrow$ means significantly decreased; means slightly fluctuated.

5.1.1. Influence Analysis of Stiffness Degradation Parameter $\alpha$. See Table 3. 


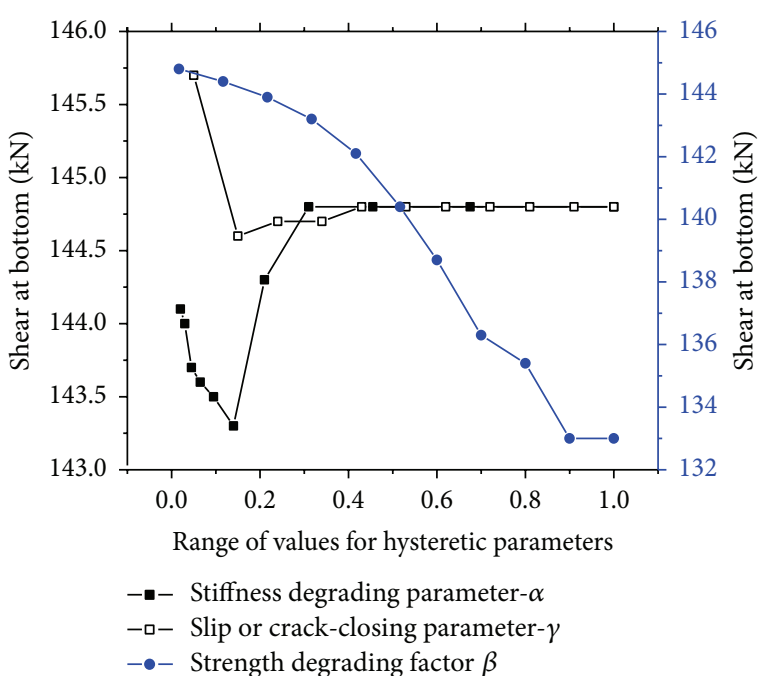

(a)

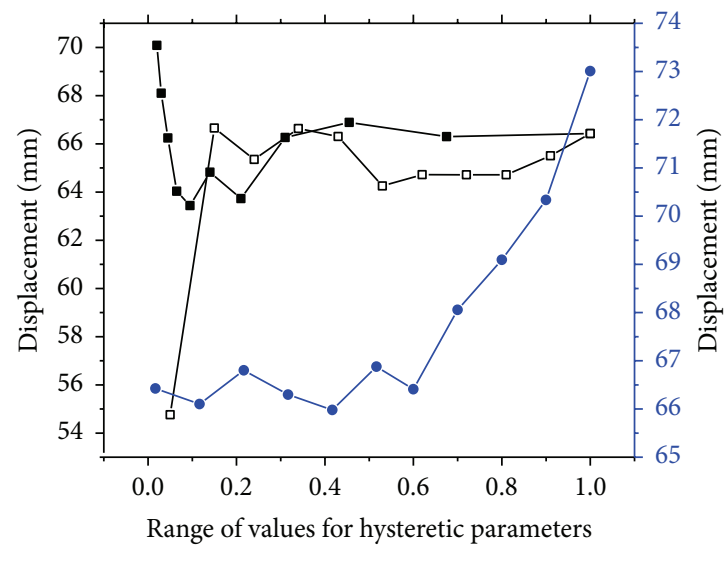

-- - Stiffness degrading parameter- $\alpha$

- - Slip or crack-closing parameter- $\gamma$

- - Strength degrading factor $\beta$

(c)

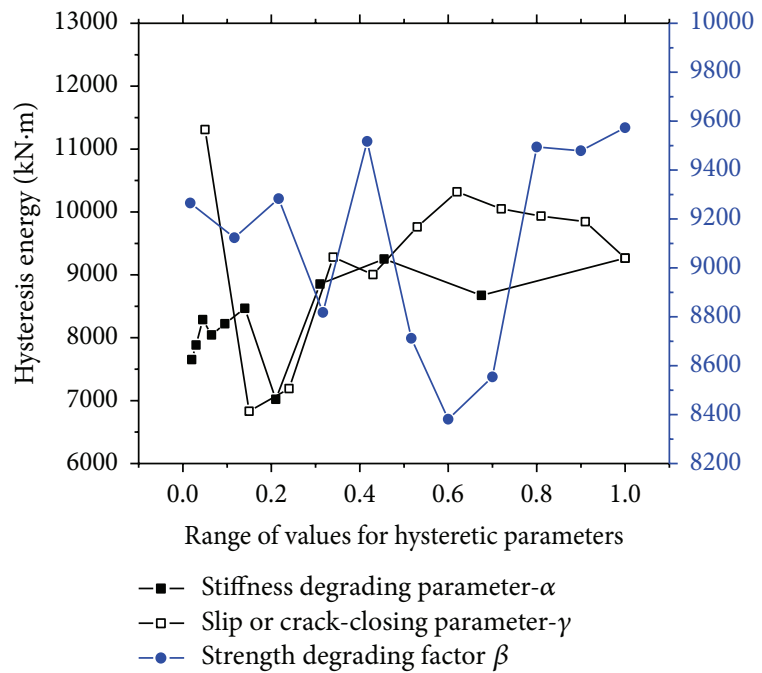

(e)

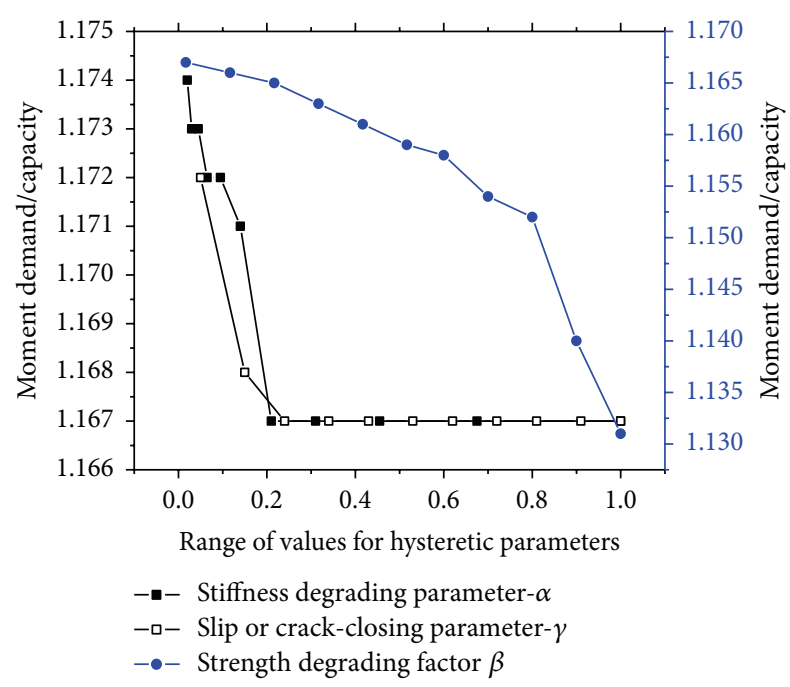

(b)

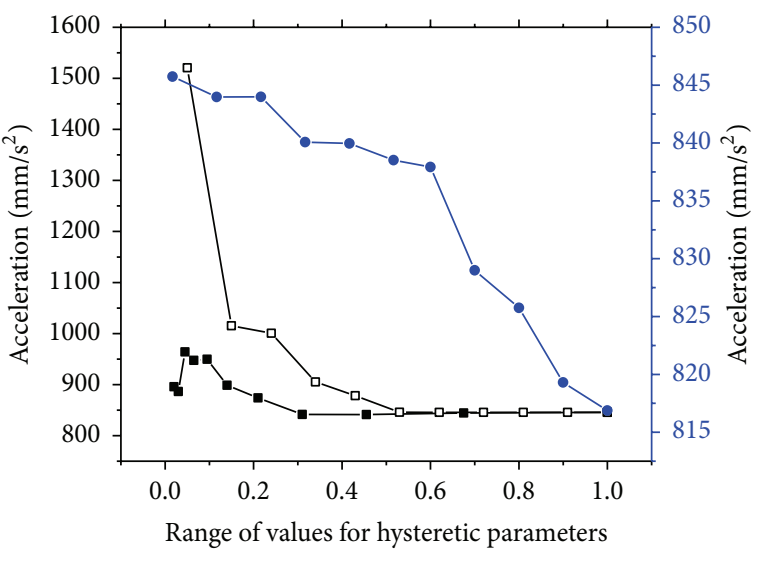

$-\bullet-$ Stiffness degrading parameter- $\alpha$
- - Slip or crack-closing parameter- $\gamma$
- - Strength degrading factor $\beta$

(d)

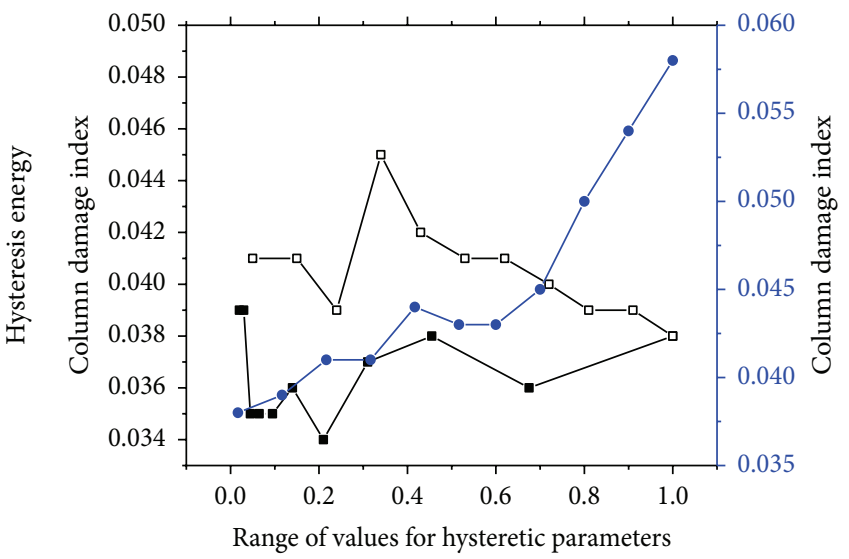

- - Stiffness degrading parameter- $\alpha$

- - Slip or crack-closing parameter- $\gamma$

- - Strength degrading factor $\beta$

(f)

FIGURE 1: Influence on main structural responses of the numerical model by varying values of energy degradation parameter $\beta$, stiffness degradation parameter $\alpha$, and fracture slip closure parameter $\gamma$. Note: for the convenience of comparative expression of various parameters in the same range, normalization processing was provided here, so that the stiffness degradation parameter $\alpha \in(1.0,0.0)$ and the energy degradation parameter $\beta \in(0.0,1.0)$. 
TABLE 3: Analytical table of the influence of varying stiffness degradation parameter $\alpha$ on structural responses and damage.

\begin{tabular}{lcccccc}
\hline $\begin{array}{l}\text { Range of control } \\
\text { parameter } \alpha\end{array}$ & $\begin{array}{c}\text { Shear force } \\
(\mathrm{kN})\end{array}$ & $\begin{array}{c}\text { Moment } \\
\text { ratio }\end{array}$ & Displacement $(\mathrm{mm})$ & Acceleration $\left(\mathrm{mm} / \mathrm{s}^{2}\right)$ & $\begin{array}{c}\text { Total energy } \\
\text { dissipation }(\mathrm{kN} \cdot \mathrm{m})\end{array}$ & $\begin{array}{c}\text { Total damage } \\
\text { value }\end{array}$ \\
\hline$\alpha \in(200 \sim 62)$ & $\rightarrow$ & $\rightarrow$ & $\rightarrow$ & $\rightarrow$ & $\sim$ & $\sim$ \\
$\alpha \in(62 \sim 28)$ & $\downarrow$ & $\uparrow$ & $\downarrow$ & $\uparrow$ & $\downarrow$ & $\downarrow$ \\
$\alpha \in(28 \sim 19)$ & $\downarrow$ & $\uparrow \uparrow$ & $\downarrow$ & $\uparrow$ & $\rightarrow$ & $\rightarrow$ \\
$\alpha \in(19 \sim 9)$ & $\downarrow$ & $\uparrow \uparrow$ & $\uparrow \uparrow$ & $\downarrow$ & $\rightarrow$ & $\rightarrow$ \\
$\alpha \in(9 \sim 4)$ & $\uparrow$ & $\uparrow \uparrow$ & $\uparrow \uparrow \uparrow$ & $\downarrow \downarrow \downarrow$ & $\downarrow \downarrow \downarrow$ & $\uparrow \uparrow \uparrow$ \\
\hline
\end{tabular}

TABLE 4: Analytical table of the influence of varying closure slip degradation parameter $\gamma$ on structural responses and damage.

\begin{tabular}{lcccccc}
\hline $\begin{array}{l}\text { Range of control } \\
\text { parameter } \gamma\end{array}$ & $\begin{array}{c}\text { Shear } \\
\text { force }(\mathrm{kN})\end{array}$ & $\begin{array}{c}\text { Moment } \\
\text { ratio }\end{array}$ & Displacement $(\mathrm{mm})$ & Acceleration $\left(\mathrm{mm} / \mathrm{s}^{2}\right)$ & $\begin{array}{c}\text { Total energy dissipation } \\
(\mathrm{kN} \cdot \mathrm{m})\end{array}$ & $\begin{array}{c}\text { Total damage } \\
\text { value }\end{array}$ \\
\hline$\gamma \in(1.0 \sim 0.62)$ & $\rightarrow$ & $\rightarrow$ & $\rightarrow$ & $\rightarrow$ & $\sim$ & $\uparrow$ \\
$\gamma \in(0.62 \sim 0.34)$ & $\downarrow$ & $\rightarrow$ & $\uparrow$ & $\uparrow$ & $\downarrow$ & $\uparrow \uparrow \uparrow$ \\
$\gamma \in(0.34 \sim 0.15)$ & $\downarrow \downarrow$ & $\uparrow \uparrow$ & $\sim$ & $\uparrow \uparrow$ & $\downarrow$ & $\uparrow \uparrow$ \\
$\gamma \in(0.15 \sim 0.05)$ & $\downarrow \downarrow \downarrow$ & $\uparrow \uparrow \uparrow$ & $\downarrow \downarrow \downarrow$ & $\uparrow \uparrow \uparrow$ & $\uparrow \uparrow \uparrow$ & $\uparrow$ \\
\hline
\end{tabular}

TABLE 5: Analytical table of the influence of varying energy degradation-based parameter $\beta$ on structural responses and damage.

\begin{tabular}{lcccccc}
\hline $\begin{array}{l}\text { Range of control } \\
\text { parameter } \beta\end{array}$ & $\begin{array}{c}\text { Shear force } \\
(\mathrm{kN})\end{array}$ & $\begin{array}{c}\text { Moment } \\
\text { ratio }\end{array}$ & Displacement $(\mathrm{mm})$ & $\begin{array}{c}\text { Acceleration }\left(\mathrm{mm} / \mathrm{s}^{2}\right) \\
\begin{array}{c}\text { Total energy dissipation } \\
(\mathrm{kN} \cdot \mathrm{m})\end{array}\end{array}$ & $\begin{array}{c}\text { Total damage } \\
\text { value }\end{array}$ \\
\hline$\beta \in(0.01 \sim 0.13)$ & $\downarrow$ & $\downarrow$ & $\sim$ & $\sim$ & $\sim$ & $\uparrow$ \\
$\beta \in(0.13 \sim 0.36)$ & $\downarrow$ & $\downarrow$ & $\sim$ & $\downarrow$ & $\downarrow$ & $\uparrow \uparrow$ \\
$\beta \in(0.36 \sim 0.48)$ & $\downarrow \downarrow$ & $\downarrow \downarrow$ & $\uparrow \uparrow$ & $\downarrow \downarrow$ & $\uparrow \uparrow$ \\
$\beta \in(0.48 \sim 0.60)$ & $\downarrow \downarrow \downarrow$ & $\downarrow \downarrow \downarrow$ & $\downarrow \downarrow \downarrow$ & $\downarrow \downarrow \downarrow$ & $\uparrow$ & $\uparrow \uparrow$ \\
\hline
\end{tabular}

\subsubsection{Influence Analysis of Closure Slip Degradation Parameter} $\gamma$. See Table 4 .

\subsubsection{Influence Analysis of Energy Degradation Parameter $\beta$.} See Table 5 and Figure 1.

5.2. Analysis of Influence of Control Parameters $\beta, \beta_{e}$, and $\beta_{d}$ on Structural Responses and Damage. Depicted in Figure 2 there are the influences on various main structural responses of the numerical model due to varying values of the energy degradation-based parameter $\beta$, of the ductilitybased strength degradation parameter $\beta_{d}$, and of the energybased strength degradation parameter $\beta_{e}$. The influences are also listed out for different value ranges of parameters $\beta_{e}$ and $\beta_{d}$ in Tables 6 and 7, respectively.

5.2.1. Influence Analysis of Energy Degradation Parameter $\beta$. The analysis results were the same with those provided in Section 5.1.3.

\subsubsection{Influence Analysis of Energy Degradation-Based Strength} Degradation Parameter $\beta_{e}$. See Table 6.

\subsubsection{Influence Analysis of Energy Degradation-Based Strength} Degradation Parameter $\beta_{d}$. See Table 7 and Figure 2.

5.3. Analysis of the Influence of Restoring Force Model Parameters on Structural Performance. Based on both the comparative analysis of the energy degradation parameter $\beta$, the stiffness degradation parameter $\alpha$ and the slip closure parameter $\gamma$, and the comparative analysis of the energy degradation parameter $\beta$, the ductility-based strength degradation parameter $\beta_{d}$, and the energy-based strength degradation parameter $\beta_{e}$, the degrees of influence of the various parameters on the main structural performance are summarized and the results of the evaluation and analysis are shown in Table 8. Meanwhile, on the basis of a comprehensive analysis of the influence of various parameters on structural responses in their variation process, value ranges are categorized into four grades (i.e., Default, Mild, Moderate, and Severe) for the five control parameters, as shown in Table 9.

After all, by the parameters values of stiffness degradation parameter $\alpha=9.0$, slip closure parameter $\gamma=0.15$, energy degradation parameter $\beta=0.54$, energy-based strength degradation parameter $\beta_{e}=0.54$, and ductility-based strength degradation parameter $\beta_{d}=0.48$, the obtained hysteretic restoring force curve and the damage evaluation of the structural members have the closest results to that of the high-performance structural member test.

\section{Conclusions}

Through studies on the most essential restoring force model within the elastoplastic dynamic time-history analysis, this paper comments on the five control parameters of the modified Park restoring model and adopts the preliminary 


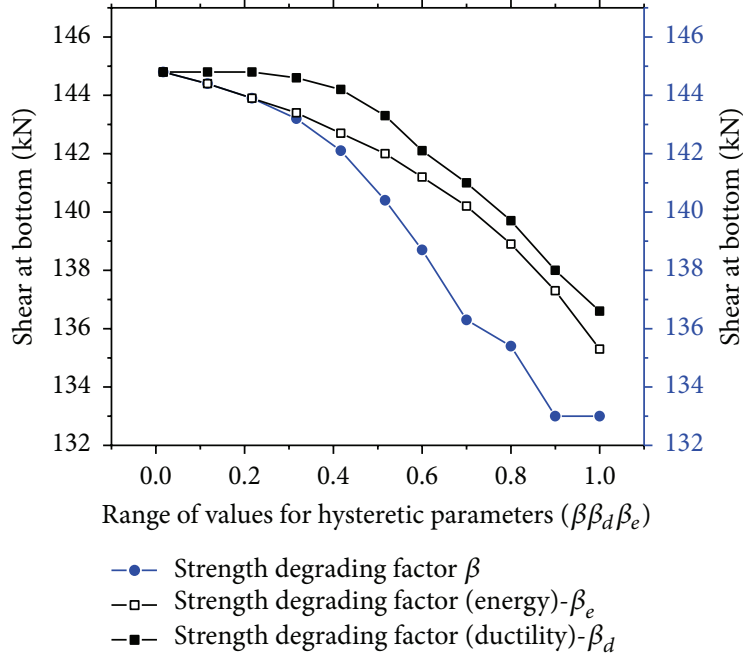

(a)

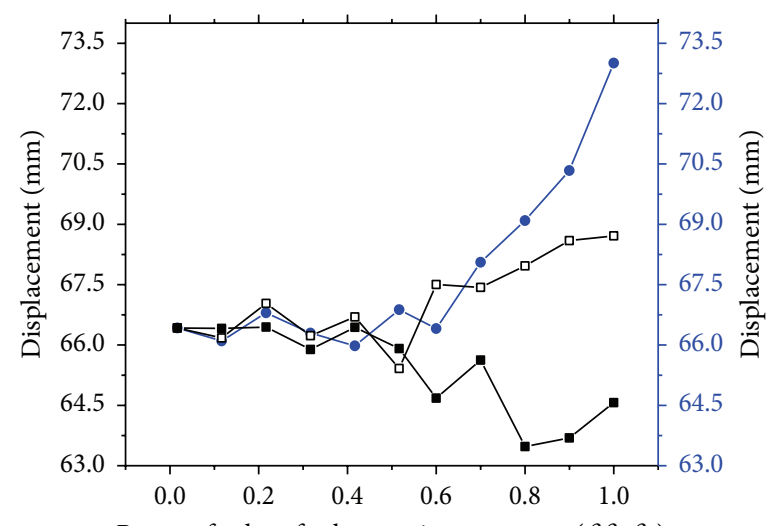

Range of values for hysteretic parameters $\left(\beta \beta_{d} \beta_{e}\right)$

- - Strength degrading factor $\beta$

$-\square-$ Strength degrading factor (energy) $-\beta_{e}$

-- Strength degrading factor (ductility)- $\beta_{d}$

(c)

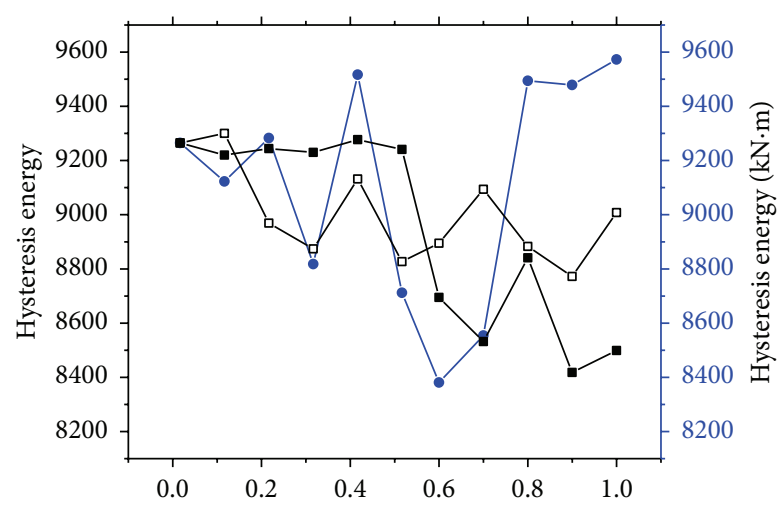

Range of values for hysteretic parameters $\left(\beta \beta_{d} \beta_{e}\right)$

- - Strength degrading factor $\beta$

$-\square-$ Strength degrading factor (energy) $-\beta_{e}$

-- Strength degrading factor (ductility)- $\beta_{d}$

(e)

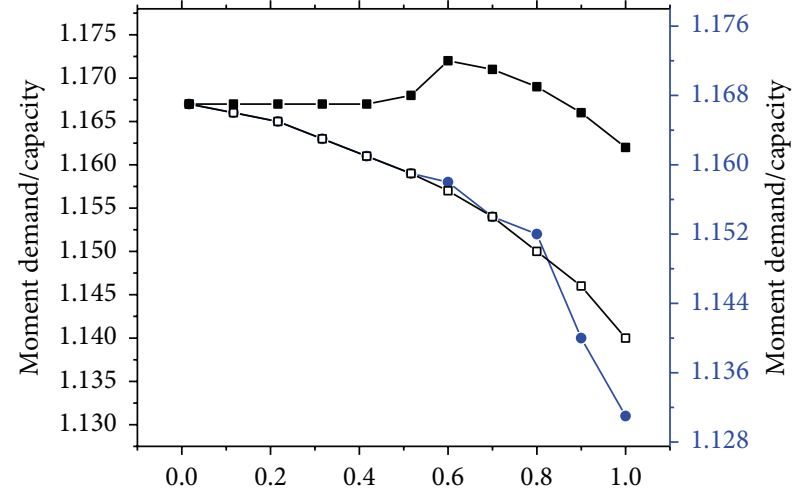

Range of values for hysteretic parameters $\left(\beta \beta_{d} \beta_{e}\right)$

-•- Strength degrading factor $\beta$

$-\square-$ Strength degrading factor (energy) $-\beta_{e}$

- - Strength degrading factor (ductility)- $\beta_{d}$

(b)

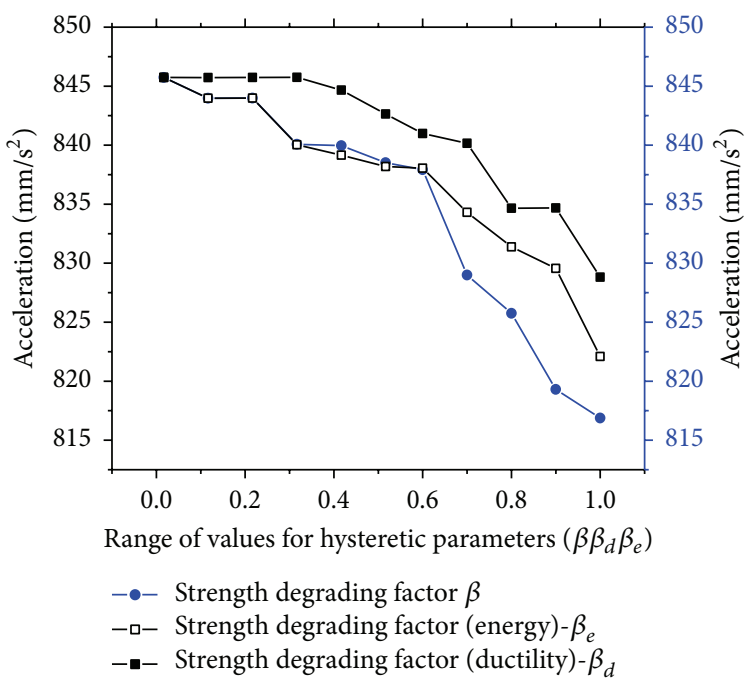

(d)

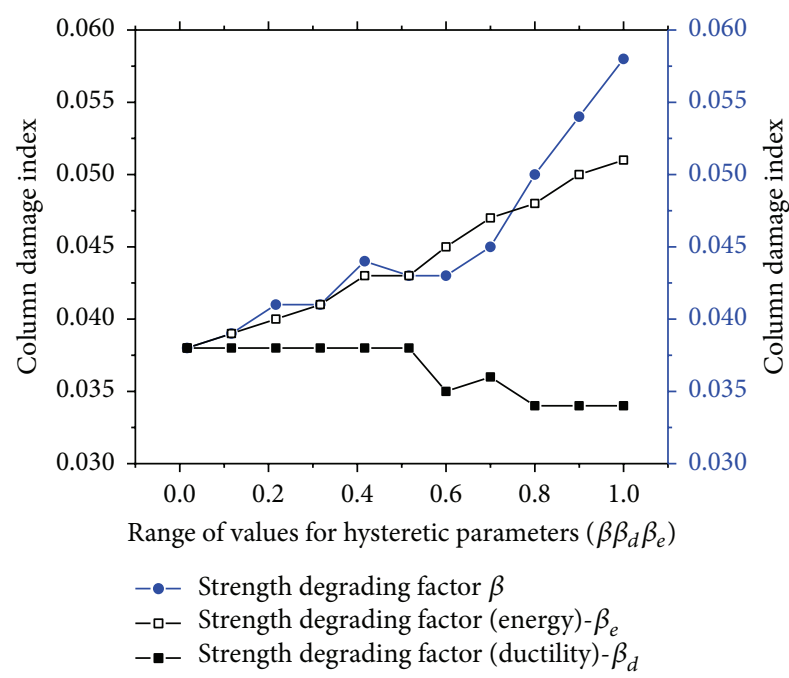

(f)

FIGURE 2: Influence on main structural responses of the numerical model by varying values of energy degradation parameter $\beta$, ductilitybased strength degradation parameter $\beta_{d}$, and energy-based strength degradation parameter $\beta_{e}$. Note: for the convenience of comparative expression of various parameters in the same range, normalization processing was provided here, so that energy degradation parameters $\beta \beta_{d} \beta_{e} \in(0.0,1.0)$. 
TABLE 6: Analytical table of the influence of varying energy-based strength degradation parameter $\beta_{e}$ on structural responses and damage.

\begin{tabular}{lccccc}
\hline $\begin{array}{l}\text { Range of control } \\
\text { parameter } \beta_{e}\end{array}$ & $\begin{array}{c}\text { Shear force } \\
(\mathrm{kN})\end{array}$ & $\begin{array}{c}\text { Moment } \\
\text { ratio }\end{array}$ & Displacement $(\mathrm{mm})$ & $\begin{array}{c}\text { Acceleration }\left(\mathrm{mm} / \mathrm{s}^{2}\right) \\
\begin{array}{c}\text { Total energy dissipation } \\
(\mathrm{kN} \cdot \mathrm{m})\end{array}\end{array}$ & $\begin{array}{c}\text { Total damage } \\
\text { value }\end{array}$ \\
\hline$\beta_{e} \in(0.01 \sim 0.13)$ & $\downarrow$ & $\downarrow$ & $\sim$ & $\sim$ & $\downarrow$ \\
$\beta_{e} \in(0.13 \sim 0.36)$ & $\downarrow$ & $\downarrow$ & $\uparrow$ & $\downarrow$ & $\sim$ \\
$\beta_{e} \in(0.36 \sim 0.48)$ & $\downarrow$ & $\downarrow \downarrow$ & $\uparrow$ & $\downarrow \downarrow$ & $\sim$ \\
$\beta_{e} \in(0.48 \sim 0.60)$ & $\downarrow \downarrow$ & $\downarrow \downarrow$ & $\uparrow$ & $\downarrow \downarrow \downarrow$ & $\sim$ \\
\hline
\end{tabular}

TABLE 7: Analytical table of the influence of varying ductility-based strength degradation parameter $\beta_{d}$ on structural responses and damage.

\begin{tabular}{lccccc}
\hline $\begin{array}{l}\text { Range of control } \\
\text { parameter } \beta_{d}\end{array}$ & $\begin{array}{c}\text { Shear force } \\
(\mathrm{kN})\end{array}$ & $\begin{array}{c}\text { Moment } \\
\text { ratio }\end{array}$ & $\begin{array}{c}\text { Displacement }(\mathrm{mm}) \\
\text { Acceleration }\left(\mathrm{mm} / \mathrm{s}^{2}\right)\end{array}$ & $\begin{array}{c}\text { Total energy dissipation } \\
(\mathrm{kN} \cdot \mathrm{m})\end{array}$ & $\begin{array}{c}\text { Total damage } \\
\text { value }\end{array}$ \\
\hline$\beta_{d} \in(0.01 \sim 0.13)$ & $\sim$ & $\sim$ & $\sim$ & $\sim$ & $\sim$ \\
$\beta_{d} \in(0.13 \sim 0.36)$ & $\downarrow$ & $\downarrow$ & $\downarrow$ & $\downarrow$ & $\downarrow$ \\
$\beta_{d} \in(0.36 \sim 0.48)$ & $\downarrow$ & $\downarrow$ & $\downarrow \downarrow$ & $\downarrow \downarrow$ & $\downarrow$ \\
$\beta_{d} \in(0.48 \sim 0.60)$ & $\downarrow \downarrow$ & $\downarrow \downarrow$ & $\downarrow$ & $\downarrow \uparrow$ & $\downarrow$ \\
\hline
\end{tabular}

TABLE 8: Influence of the five control parameters of the modified Park restoring force model on structural responses.

\begin{tabular}{|c|c|c|c|c|c|c|}
\hline Control parameter & $\begin{array}{c}\text { Shear value } \\
(\mathrm{kN})\end{array}$ & $\begin{array}{c}\text { Moment } \\
\text { ratio }\end{array}$ & Displacement (mm) & Acceleration $\left(\mathrm{mm} / \mathrm{s}^{2}\right)$ & $\begin{array}{c}\text { Total energy } \\
\text { dissipation }(\mathrm{kN} \cdot \mathrm{m}) \\
\end{array}$ & $\begin{array}{c}\text { Total damage } \\
\text { value }\end{array}$ \\
\hline $\begin{array}{l}\text { Stiffness degradation } \\
\text { parameter } \alpha\end{array}$ & $\star \star$ & $\star \star$ & $\star$ & $\star$ & $\star \star$ & $\star$ \\
\hline $\begin{array}{l}\text { Slip or fracture closure } \\
\text { parameter } \gamma\end{array}$ & $\star$ & $\star$ & $\star \star$ & $\star \star$ & $\star$ & $\star$ \\
\hline $\begin{array}{l}\text { Energy degradation } \\
\text { parameter } \beta\end{array}$ & $\star \star \star$ & $\star \star \star$ & $\star \star \star$ & $\star \star \star$ & $\star \star \star$ & $\star \star \star$ \\
\hline $\begin{array}{l}\text { Energy-based strength } \\
\text { degradation parameter } \beta_{e}\end{array}$ & $\star \star \star$ & $\star \star \star$ & $\star \star \star$ & $\star \star \star$ & $\star \star \star$ & $\star \star \star$ \\
\hline $\begin{array}{l}\text { Ductility-based strength } \\
\text { degradation parameter } \beta_{d}\end{array}$ & $\star \star$ & $\star$ & $\star$ & $\star \star$ & $\star \star \star$ & is \\
\hline
\end{tabular}

Note: “ $\star \star \star$ ”: relatively significant influence; “ $\star \star$ ”: moderate influence; “ $\star$ ”: relatively insignificant influence; “活”: no or little influence.

TABLE 9: Value ranges proposed for the five control parameters of the modified Park restoring force model.

\begin{tabular}{lcccc}
\hline Control parameter & Default & Mild & Moderate & Severe \\
\hline $\begin{array}{l}\text { Stiffness degradation } \\
\text { parameter } \alpha\end{array}$ & $\alpha \in(200 \sim 62)$ & $\alpha \in(62 \sim 28)$ & $\alpha \in(28 \sim 9)$ & $\alpha \in(9 \sim 4)$ \\
$\begin{array}{l}\text { Slip } \text { or fracture closure } \\
\text { parameter } \gamma\end{array}$ & $\gamma \in(1.0 \sim 0.62)$ & $\gamma \in(0.62 \sim 0.34)$ & $\gamma \in(0.34 \sim 0.15)$ & $\gamma \in(0.15 \sim 0.05)$ \\
$\begin{array}{l}\text { Energy degradation } \\
\text { parameter } \beta\end{array}$ & $\beta \in(0.01 \sim 0.13)$ & $\beta \in(0.13 \sim 0.36)$ & $\beta \in(0.36 \sim 0.48)$ & $\beta \in(0.48 \sim 0.60)$ \\
$\begin{array}{l}\text { Energy-based strength } \\
\text { degradation parameter } \beta_{e}\end{array}$ & $\beta_{e} \in(0.01 \sim 0.13)$ & $\beta_{e} \in(0.13 \sim 0.36)$ & $\beta_{e} \in(0.36 \sim 0.48)$ & $\beta_{e} \in(0.48 \sim 0.60)$ \\
$\begin{array}{l}\text { Ductility-based strength } \\
\text { degradation parameter } \beta_{d}\end{array}$ & $\beta_{d} \in(0.01 \sim 0.13)$ & $\beta_{d} \in(0.13 \sim 0.36)$ & $\beta_{d} \in(0.36 \sim 0.48)$ & $\beta_{d} \in(0.48 \sim 0.60)$ \\
\hline
\end{tabular}

quasistatic test data to analyze the influence of these five parameters on the structural performances of high-strength concrete column members, such as shear value, moment value ratio, displacement value, acceleration value, total energy dissipation, and total damage value.

The results of the study indicates that the energy degradation parameter $\beta$ exerts an essential control effect on the main performances of structural members; the energybased strength degradation parameter $\beta_{e}$ exerts a degree of influence consistent with $\beta$; the stiffness degradation parameter $\alpha$ relatively significantly influences the shear value and moment value of structural members; the slip or fracture closure parameter $\gamma$ relatively significantly influences their displacement and acceleration response; and the 
ductility-based strength degradation parameter $\beta_{d}$ relatively obviously influences their shear value, moment value, and total energy dissipation.

At the end, on the basis of a comprehensive analysis of the influence of various parameters on structural responses in their variation process, value ranges are categorized into four grades (i.e., Default, Mild, Moderate, and Severe) for the five control parameters as shown in Table 9. Considering also the quasistatic test of high-performance columns, it proposed the value ranges of the five control parameters, that is, stiffness degradation parameter $6 \leq \alpha \leq 9$, slip closure parameter $0.15 \leq \gamma \leq 0.05$, energy degradation parameter $0.54 \leq$ $\beta \leq 0.60$, energy-based strength degradation parameter $0.54 \leq \beta_{e} \leq 0.60$, and ductility-based strength degradation parameter $0.48 \leq \beta_{d} \leq 0.54$.

\section{Competing Interests}

The authors of paper declare that there are no competing interests regarding the publican of this paper. The authors do not have a direct financial relation with the commercial identity that might lead to competing interests for any of the authors.

\section{Acknowledgments}

This work is supported by Natural Science Foundation of China (Grant no. 50578066) and Project of National Public Welfare Industry Research (201111020-2). The authors sincerely thank them for their support and funding.

\section{References}

[1] W. B. Krätzig and Y. S. Petryna, "Quasistatic seismic damage indicators for RC structures from dissipating energies in tangential subspaces," Mathematical Problems in Engineering, vol. 2014, Article ID 615792, 11 pages, 2014.

[2] M. V. Sivaselvan, "Hysteretic models with stiffness and strength degradation in a mathematical programming format," International Journal of Non-Linear Mechanics, vol. 51, pp. 10-27, 2013.

[3] T. Ray and A. M. Reinhorn, "Enhanced smooth hysteretic model with degrading properties," Journal of Structural Engineering, vol. 140, no. 1, pp. 896-912, 2014.

[4] Y. J. Park, A. M. Reinhorn, and S. K. Kunnath, IDARC: Inlastic Damage Analysis of Reinforced Concrete Frame-shearwall Structures, National Center for Eaathquake Engineering Research,State University of New York at Buffalo, Buffalo, NY, USA, 1987.

[5] A. M. Reinhorn, H. Roh, M. V. Sivaselvan et al., IDARC2D Version 7.0: A Program for the Inelastic Damage Analysis of Structures, University at Buffalo, State University of New York, Buffalo, NY, USA, 2009.

[6] M. V. Sivaselvan and A. M. Reinhorn, "Hysteretic models for deteriorating inelastic structures," Journal of Engineering Mechanics-ASCE, vol. 126, no. 6, pp. 633-640, 2000.

[7] R. W. Clough and S. B. Johnston, Effect of Stiffness Degradation on Earthquake Ductility Requirements, Department of Civil Engineering, University of California, Berkeley, Calif, USA, 1966.
[8] T. Takeda, M. A. Sozen, and N. N. Nielsen, "Reinforced concrete response to simulated earthquakes," Journal of the Structural Division, vol. 96, no. 12, pp. 2557-2573, 1970.

[9] T. Kabeyasawa, H. Shioara, and S. Otani, "US-Japan cooperative research on RC full scale building test-Part5:discussion on dynamic response system," in Proceedings of the 8th World Conference on Earthquake Engineering, pp. 627-634, San Francisco, Calif, USA, 1984.

[10] Y. Park and A. Ang, "Mechanistic seismic damage model for reinforced concrete," Journal of Structural Engineering, vol. 111, no. 4, pp. 722-739, 1985.

[11] M. V. Sivaselvan and A. M. Reinhorn, "Hysteretic models for deteriorating inelastic structures," Journal of Engineering Mechanics, vol. 127, no. 6, pp. 633-640, 2001.

[12] Y. J. Park, A. H. Ang, and Y. K. Wen, "Damage-limiting aseismic design of buildings," Earthquake Spectra, vol. 3, no. 1, pp. 1-26, 1987.

[13] R. Rajabi, M. Barghi, and R. Rajabi, "Investigation of ParkAng damage index model for flexural behavior of reinforced concrete columns," Structural Design of Tall \& Special Buildings, vol. 22, no. 17, pp. 1350-1358, 2013.

[14] C. Wang, J. Xiao, and Z. Sun, "Seismic damage assessment on cast-in-situ recycled aggregate concrete frame model structure," Journal of Tongji University, vol. 43, no. 2, pp. 167-174, 2015 (Chinese).

[15] L. Chen, H. Jiang, and X. Lu, "Modified Park-Ang damage model for reinforced concrete structures," Journal of Tongji University, vol. 38, no. 8, pp. 1103-1107, 2010 (Chinese).

[16] H.-B. Lin, S.-G. Tang, and C. Lan, "Damage analysis and evaluation of high strength concrete frame based on deformationenergy damage model," Mathematical Problems in Engineering, vol. 2015, Article ID 781382, 14 pages, 2015.

[17] H. Lin and Q. Wang, "Seismic behavior on HRB400 highstrength reinforced concrete columns," Journal of Building Structures (China), vol. 29, supplement 1, pp. 36-41, 2008.

[18] H. Lin and Q. Wang, "Damage evaluation of high-strength renforced concrete Structure based on IDRAC," Journal of Building Structures, vol. 29, no. 1, pp. 255-259, 2008.

[19] D. C. Kent and R. Park, "Flexural members with confined concrete," Journal of the Structural Division, vol. 97, no. 7, pp. 1969-1990, 1971.

[20] B. D. Scott, R. Park, and M. J. N. Priestley, "Stress-strain behavior of concrete confined by overlapping hoops at low and high strain rates," Journal of the American Concrete Institute, vol. 79, no. 1, pp. 13-27, 1982. 

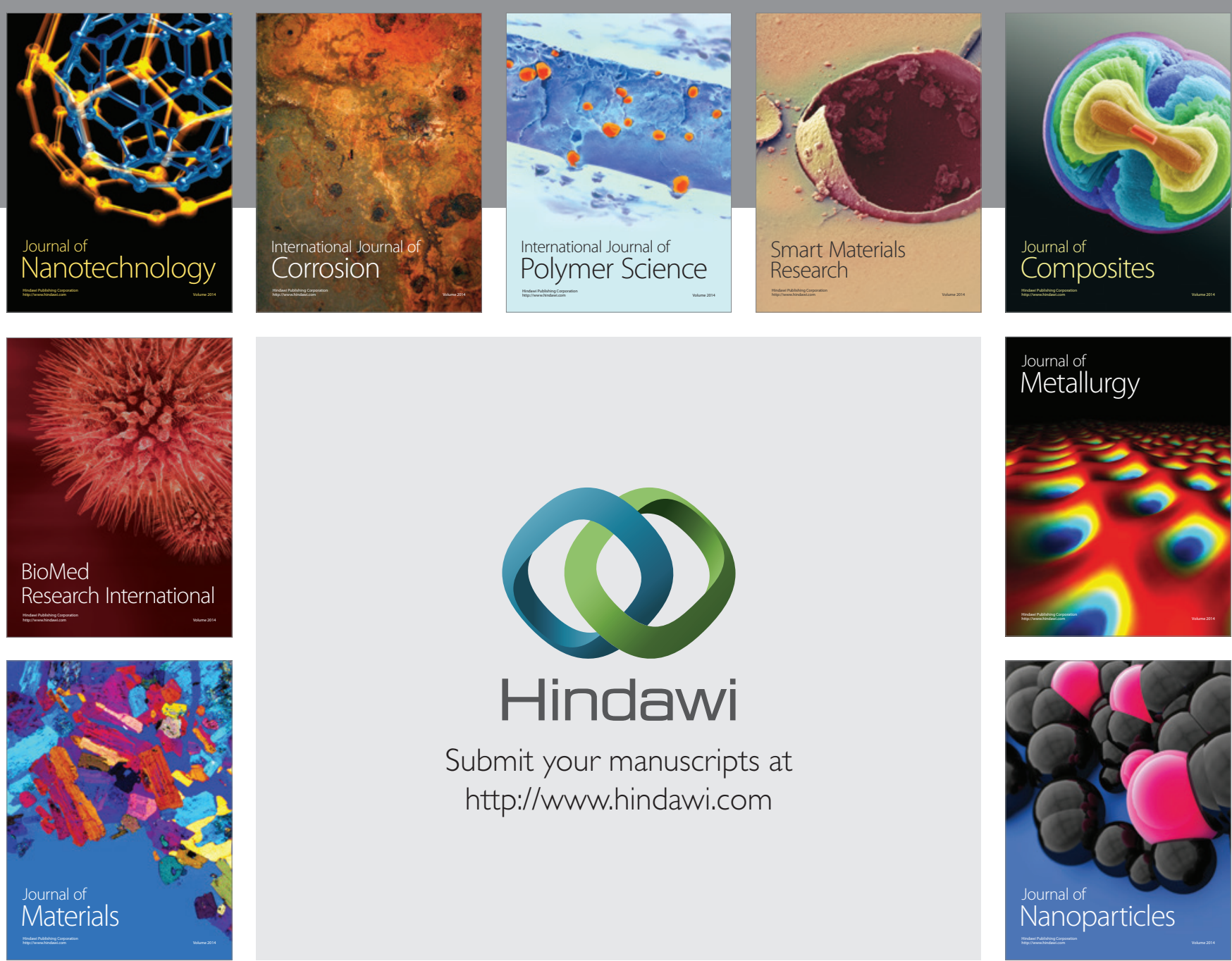

\section{Hindawi}

Submit your manuscripts at

http://www.hindawi.com

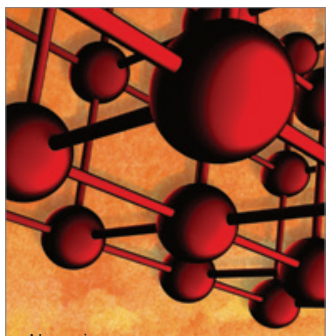

Materials Science and Engineering
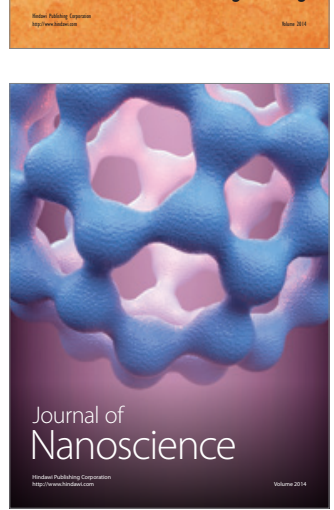
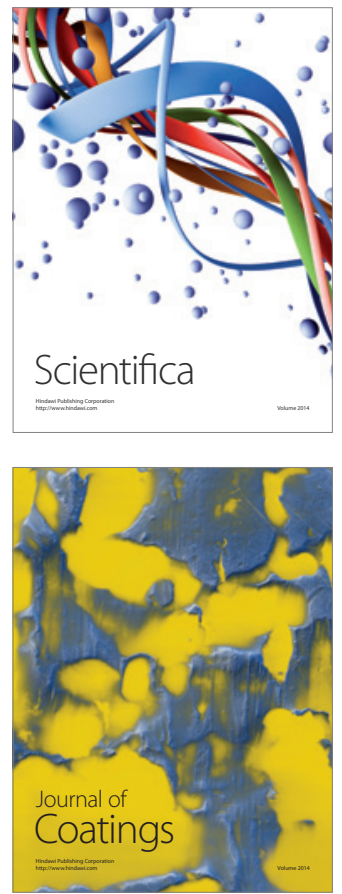
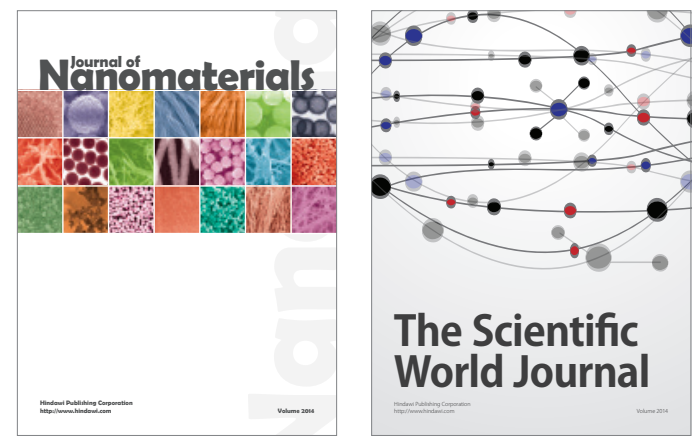

The Scientific World Journal
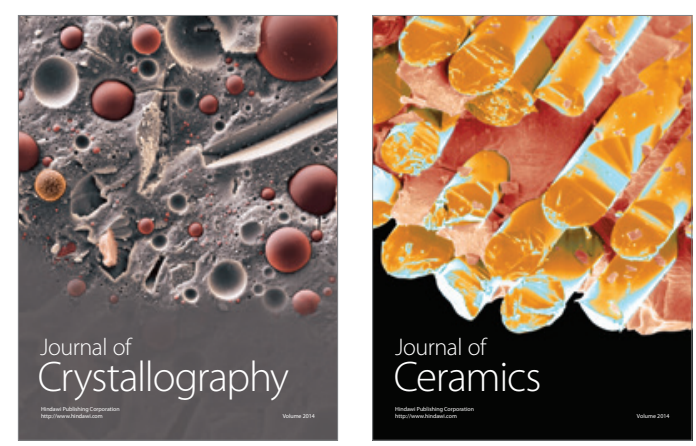
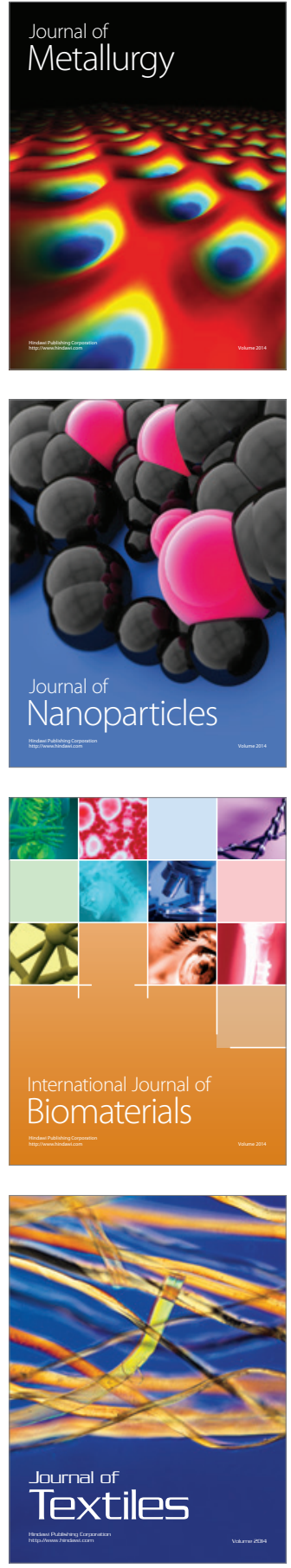